\title{
Fine Needle Aspiration Cytology and Cell Block Study of Various Breast Lumps
}

Mahima Jatin Patel* and Smita C Patel

Department of Pathology, Baroda Medical College, Maharaja Sayajirao University, Vadodara, Gujarat, India

*Corresponding author: Patel MJ, Department of Pathology, Baroda Medical College, Maharaja Sayajirao University, Vadodara, Gujarat, India, Tel: 9824515742; Email: dr.mahimapatel37@gmail.com

Received date: July 21, 2018; Accepted date: July 31, 2018; Published date: August 03, 2018

Copyright: (c) 2018 Patel MJ, et al. This is an open-access article distributed under the terms of the Creative Commons Attribution License, which permits unrestricted use, distribution, and reproduction in any medium, provided the original author and source are credited.

\begin{abstract}
Aim of the study was to evaluate the importance of the combined use of fine needle aspiration cytology (FNAC) and cell block in the diagnosis of breast lesions. A total of 33 cases with breast swelling were included in the study of which FNAC, cell block and biopsy or resected specimens were available. Cytological finding of smears and cell blocks were correlated to histo pathological results, with the combined use of FNAC and cell block, specificity, positive and negative predictive value were $100 \%$ while sensitivity and accuracy were $96 \%$. Major limitation of breast FNAC compared with core needle biopsy is inability to determine invasion in carcinoma. Of 17 carcinomas, invasion could be identified in 10 cases $(59 \%)$ in cell block sections. Cell blocks complement smears and monolayers and appear to overcome major limitations of breast FNAC.
\end{abstract}

Keywords: Immunohistochemistry; Fine needle aspiration cytology (FNAC); Core needle biopsy; Diagnosis

\section{Introduction}

Fine needle aspiration cytology (FNAC) for diagnosis of various neoplastic lesions is a well-established procedure. This procedure is widely practiced, minimally invasive, cost-effective and safe method. However sometimes fine needle aspiration (FNA) does not yield sufficient information for precise diagnosis and the risk of false negative or intermediate diagnosis always exists [1]. Early definitive diagnosis of breast masses is important in FNAC negative cases. On the other hand, core needle biopsy (CNB) is thought to provide a more exact diagnosis of breast tumors [2], especially in cases of non-palpable breast tumors. However, $\mathrm{CNB}$ is not widely used, because it takes more time and often necessitates anesthesia. Combined utility of FNAC with core needle biopsy has shown to increase the diagnostic accuracy [2]. In this study, we investigate the use of combining the breast FNAC smear with cell blocks in diagnosis of breast lesions instead of CNB, and whether it gives the advantage of both approaches.

\section{Objectives}

This study aimed to evaluate combined use of fine needle aspiration cytology and cell block in the diagnosis of different breast lesions and to evaluate the diagnosing utility of cell block with respect to fine needle aspiration cytology by comparing diagnosis of various breast lesions attained with the help of fine needle aspiration cytology and cell block with the histopathological diagnosis given for the same. Immunohistochemistry markers were applied over cell block in the diagnostic dilemmas.

\section{Materials and Methods}

The present study enrolled 33 patients with breast lumps referred to cytopathology unit, Shree Sayajirao general hospital, Vadodara during a period of 1 year (from December 2015 to December 2016). Consent was obtained in local language from patient. Clinical history and local as well as systemic examination were recorded in proforma (Case record form). Aspirates were obtained with a 22 gauge needle and a 10 $\mathrm{ml}$ syringe, and the needle was moved in many directions under vaccum. Conventional smears were stained with $\mathrm{H} \& \mathrm{E}$, Papanicolau (PAP) and giemsa. For making cell block, remaining material in the aspirating syringe, after making enough conventional cytology smears, was clotted and the formed cell button was allowed to fix in $10 \%$ neutral buffered formalin for $12 \mathrm{~h}$. Then cell button was removed carefully and wrapped in a Whatman filter and placed in cassette. This sample was then processed as surgical tissue in automated tissue processor. FNAC smears and cell block sections were examined separately for cellularity and reported. Immunohistochemistry was done in diagnostic dilemmas. All the FNAC smears were categorized [3], benign (specific) including cyst, fibroadenoma, intramammmary lymph node-C-I, Benign (Nonspecific)-C-II, Atypical or indeterminate-C-III, Suspicious of malignancy-C-IV and Positive for malignancy-C-V. According to cellularity, the smears and cell blocks were first divided into- Inadequate and Adequate. Inadequate smears or cell block sections were those, which showed only blood or less cellularity for diagnosis. Inadequate FNAC smears (acellular or bloody samples with poorly preserved cells) were excluded and repeat FNAC was performed. All the remaining smears or cell blocks were considered as adequate.

Whereas all the adequate cell block sections were categorized as: Non-contributory- FNAC smears were adequate, but cell blocks were inadequate, Confirms the Diagnosis - cell blocks gave the same diagnosis as that of the FNAC smears and Establishes a Specific Diagnosis - the cases in which FNAC smears failed to give correct diagnosis but cell block gave the diagnosis.

The diagnosis on FNAC smears and cell block were confirmed by histopathology and compared with each other. The cases, for which histopathology reports were not available, were excluded from the study. Each of the below mentioned five criteria should be fulfilled for diagnosis of invasion from cell block sections of breast malignancies 
Page 2 of 5

[4], presence of malignant cells within stromal tissue, without a normal lobular contour, without evident adjacent myoepithelial cells, with a random pattern to tissue landmark and with some activation of adjacent stromal cells.

\section{Results}

Total 33 cases were included in our study, out of which 33 were diagnosed on FNAC smears and 32 were diagnosed on cell block sections.

\begin{tabular}{|l|l|l|l|}
\hline Diagnosis & FNAC & Cell block & HP \\
\hline Fibroadenoma & 4 & 4 & 4 \\
\hline Benign breast lesions & 5 & 4 & 4 \\
\hline Inflammatory smear & 2 & 2 & 2 \\
\hline Phyllodes tumor & 0 & 1 & 1 \\
\hline Benign breast lesion & 3 & 1 & 1 \\
\hline Infiltrating ductal carcinoma & 20 (mammary carcinoma) & 10 (Infiltrating ductal carcinoma) & 18 (Infiltrating ductal carcinoma) \\
\hline Metaplastic carcinoma of breast & 10 (ductal carcinoma) & 2 (ductal carcinoma) \\
\hline $\begin{array}{l}\text { Non Hodgkin lymphoma } \\
\text { Non Hodgkin lymphoma/neuroendocrine tumor) }\end{array}$ & 1 & 0 & 1 \\
\hline $\begin{array}{l}\text { Mucinous carcinoma } \\
\text { (?Mucinous/?Papillary carcinoma) }\end{array}$ & 1 & 1 & 1 \\
\hline Atypical ductal hyperplasia & 1 & 3 & 3 \\
\hline Suspicious for malignancy & 1 & 0 & 0 \\
\hline Inadequate & 0 & 33 & 0 \\
\hline Total & 33 & 1 & 33 \\
\hline
\end{tabular}

Table 1: Distribution of cases according to FNAC, cell block and histopathology diagnosis.

On FNAC smears, 4 cases were diagnosed as fibroadenoma, these findings correlated with the cell block and histopathology diagnosis (Table 1).

On FNAC smears, 5 cases were diagnosed as benign breast lesion. Out of these 5 cases, 3 ( 2 cases of inflammatory smear and 1 benign breast lesion) were correlated with the cell block diagnosis and histopathology diagnosis. 1 case diagnosed as benign breast lesion on FNAC was of benign phyllodes tumor (on cell block and histopathology). Another case diagnosed as benign breast lesion on FNAC was diagnosed as ductal carcinoma on cell block and invasive ductal carcinoma on histopathology specimen.

On FNAC smears, 20 cases were diagnosed as mammary carcinoma. FNAC has failed to establish a definitive diagnosis among 2 cases while cell block has failed to do so in 1 case. 1 case was diagnosed as mucinous carcinoma on cell block and histopathology both while another case was diagnosed on cell block as ductal carcinoma but metaplastic carcinoma of breast on histopathology. On FNAC smear, two possibilities were made: 1) Non Hodgkin lymphoma and 2) Neuroendocrine tumor which correlated with cell block and histopathology diagnosis of Non Hodgkin lymphoma (Table 1).

1 case diagnosed as (mucinous carcinoma/papillary carcinoma) on FNAC smear turned out to be mucinous carcinoma on cell block and histopathology.1 case diagnosed as atypical ductal hyperplasia on FNAC smear turned out to be mucinous carcinoma on cell block and histopathology.1 case diagnosed as suspicious for malignancy on FNAC smear turned out to be invasive ductal carcinoma on histopathology while cell block was inadequate for the same case (Table 1).

\begin{tabular}{|c|c|c|c|c|c|c|}
\hline $\begin{array}{l}\text { Malignant cells } \\
\text { within the stroma }\end{array}$ & $\begin{array}{l}\text { Without a } \\
\text { normal lobular } \\
\text { contour }\end{array}$ & $\begin{array}{lr}\text { Without } & \text { evident } \\
\text { adjacent } & \text { myoepithelial } \\
\text { cells } & \end{array}$ & $\begin{array}{l}\text { Random pattern to } \\
\text { tissue landmark }\end{array}$ & 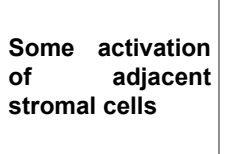 & $\begin{array}{l}\text { No of cases which } \\
\text { fulfilled all the five } \\
\text { diagnostic criteria of } \\
\text { invasion }\end{array}$ & $\begin{array}{l}\text { Infiltrating } \\
\text { carcinoma } \\
\text { histopathology } \\
\text { adequate cell } \\
\text { material }\end{array}$ \\
\hline $10(58.8 \%)$ & $17(100 \%)$ & $17(100 \%)$ & $17(100 \%)$ & $10(59 \%)$ & $10(59 \%)$ & 17 \\
\hline
\end{tabular}

Table 2: Distribution of cases of infiltrating ductal carcinoma according to criteria of invasion applied on cell block. 
In the present study, from total 18 cases of infiltrative carcinoma of breast diagnosed on histopathology, 17 cases had adequate cell block material for the diagnosis. All the $17(100 \%)$ cases have shown (Table 2).

- Random pattern to tissue landmark,

- Absence of myoepithelial cells,

- Loss of normal lobular contour.

While 7 cases have failed to fulfill two criteria (Table 2).

- Malignant cells within the stroma,

- Activation of adjacent stromal cells.

Total 10 (59\%) cases have fulfilled all the five diagnostic criteria of invasion (Table 2).

\section{Discussion}

In our study, $10 \%$ neutral buffered formalin was used as a fixative for the cell block. It is a more practical fixative than others as it allows wide range of additional procedures [5]. Another advantage is that it is readily available in the laboratories. This fixative was also used in the study of Basnet et al. Wide range of histologic fixatives have been used for cell blocks: primarily buffered formalin, neutral buffered formaldehyde solution, Bouin's solution, picric acid fixative, carnoy fixative and ethanol $[1,6,7]$.

Out of 32 adequate cases on both FNAC smears and cell blocks, 26 (81\%) cases had concordant diagnosis between FNAC smears and cell blocks whereas $6(19 \%)$ cases had discordant diagnosis in which cell block has provided additional information and has established a specific diagnosis in 6 cases while FNAC smears have failed to do so.

In concordant cases, though diagnosis on FNAC smears and cell blocks were same, cell block showed architectural patterns and additional diagnostic information, which confirmed diagnosis on FNAC smears.

Total 3 cases of mucinous carcinoma of breast were diagnosed in the present study. In one case, two possibilities were made from fine needle aspiration cytology: 1) mucinous carcinoma and 2) papillary carcinoma. Other two cases were diagnosed as mammary carcinoma and atypical ductal hyperplasia respectively from fine needle aspiration cytology. In all 3 cases of mucinous carcinoma, cell block has shown excellent histopathology image of malignant cells entrapped in extracellular mucin providing definitive diagnosis of mucinous carcinoma. Cell block has helped to exclude the possibility of mucocele as cells were entrapped in abundant extracellular mucin (Figure 1). Thus fine needle aspiration cytology alone has failed to diagnose mucinous carcinoma in two cases and directed the diagnosis of mucinous carcinoma in one case while cell block has given definitive diagnosis of mucinous carcinoma in all 3 cases.

In case of Non Hodgkin lymphoma of breast, from FNAC smears, two possibilities were given: 1) Non Hodgkin lymphoma and 2) neuroendocrine tumor as smears have shown dispersed population of small, round cells having hyperchromatic nuclei and scant cytoplasm in background of lymphocytes. Cell block has also provided same cytological image with occasional benign breast ducts. Panel of IHC markers were applied on cell block sections. Markers applied were: Synaptophysin, Chromogranin, CD20, CD79a and CD5. CD 20 was strong and diffuse cytoplasmic positive in small malignant tumor cells (Figure 2) while rest of the markers were negative. Thus in this case cell block has given the definitive diagnosis of Non Hodgkin lymphoma of breast with the help of immunohistochemistry.

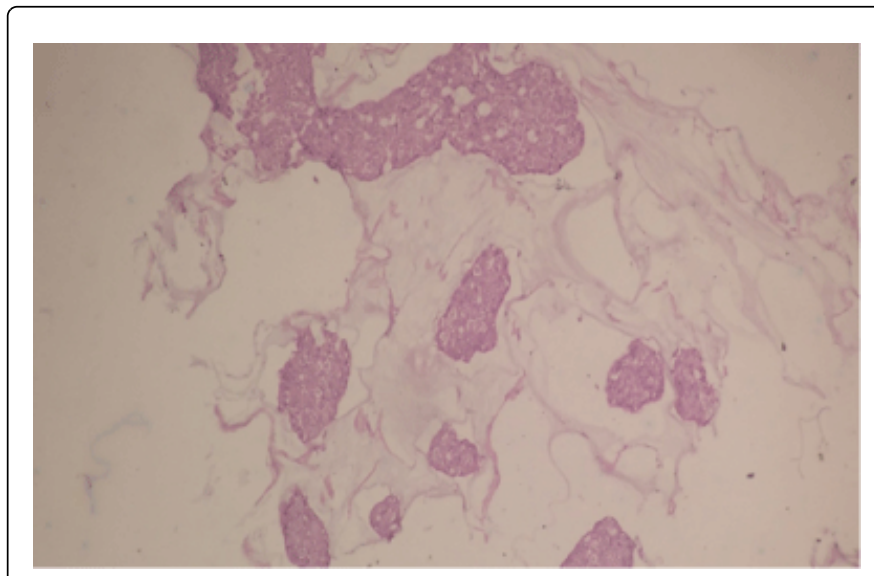

Figure 1: Photomicrograph showing sheets of tumor cells with mild atypia and focal cribriform pattern entrapped in pools of extracellular mucin in cell block (x200, H\&E stain): Mucinous carcinoma of breast.

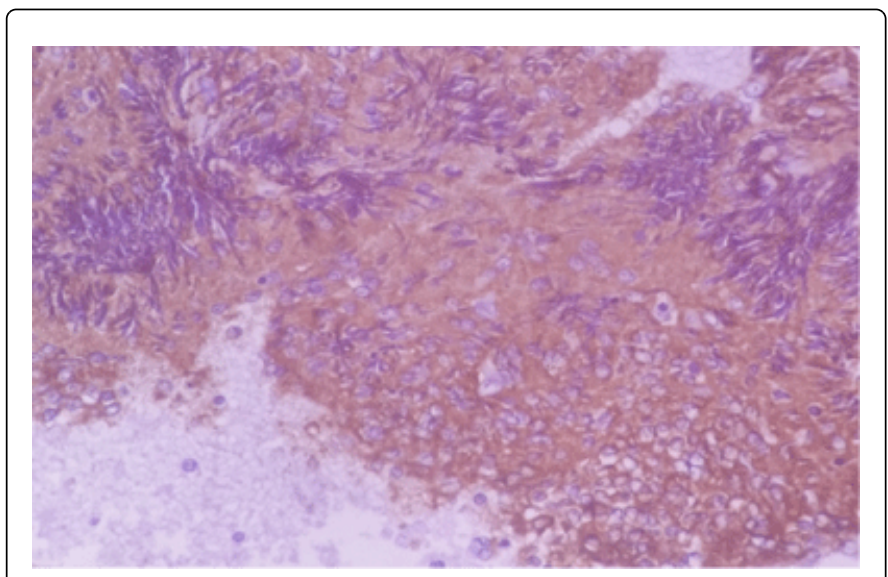

Figure 2: Photomicrograph showing cytoplasmic CD20 strong positivity in small malignant round cells in cell block (x400): Non Hodgkin lymphoma of breast.

In a case diagnosed as benign breast lesion on FNAC, cell block has shown dispersed cells with moderate nuclear atypia (pleomorphism and hyperchromasia) along with some benign ducts. Diagnosis of ductal carcinoma was made on cell block which correlated with the histopathology diagnosis of infiltrative ductal carcinoma diagnosed as benign breast lesion on FNAC. One case was diagnosed as having benign breast lesion on FNAC as there were benign ductal epithelial cells in tight clusters while in similar case, cell block has shown abundant stromal tissue along with occasional benign ducts. Thus the diagnosis of benign phyllodes tumor was made from the cell block which correlated with the histopathological diagnosis.

Thus FNAC diagnosis was false negative in this case. Both FNAC and cell block has failed to give a definitive diagnosis of metaplastic carcinoma of breast. This indicates inherent limitation of fine needle aspiration technique as needle might not have penetrated the metaplastic foci of breast. 


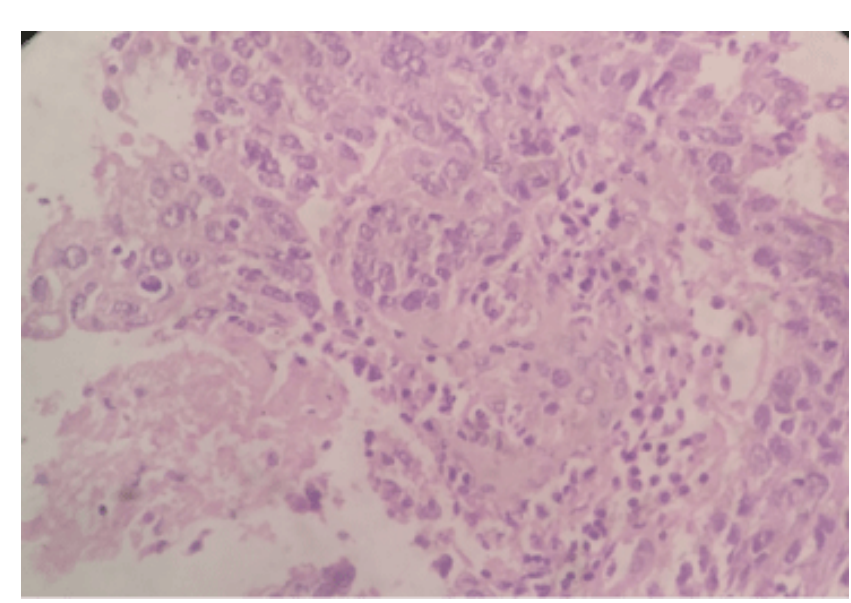

Figure 3: Photomicrograph showing malignant cells with ductal pattern in stroma along with foci of necrosis diagnosed as invasive ductal carcinoma on cell block (x400, H\&E stain).

Among total 20 cases diagnosed on cell block as ductal carcinoma, most common pattern observed was ductal pattern. Second common pattern was solid pattern. Nuclear atypia was present in all 20 (100\%) cases. Necrosis was the second most common observed feature of malignancy.

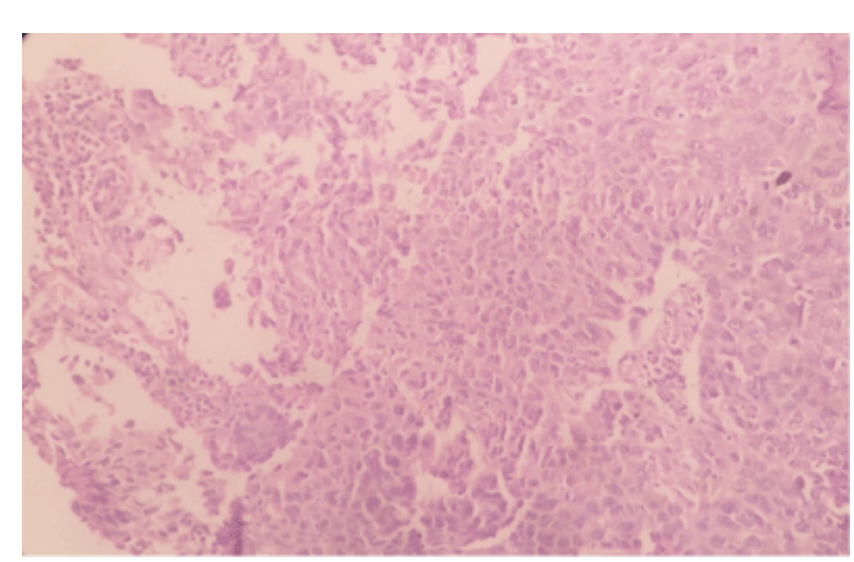

Figure 4: Photomicrograph showing malignant cells in the stroma having solid pattern on cell block (x200, H\&E stain).

In the present study, invasion was diagnosed in 10/17 (59\%) of the diagnosed ductal carcinomas (Figures 3 and 4). The presence of invasion was underestimated in $41 \%$ of cases (Table 2). These findings were comparable to the study of Smiljana Istvanic et al. in which cell block has diagnosed invasion in $46 \%$ of the diagnosed ductal carcinoma while underestimation was in $54 \%$ of cases [4].

The presence of invasion is underestimated in $15-36 \%$ of core needle biopsies. Interestingly, the underestimation of invasion is the same for an 11 gauge vacuum assisted core needle biopsy as a 14 gauge core needle biopsy [8]. Cell block has shown percentage of underestimation (41\%) which was quite nearer to the values of core needle biopsy (15-36\%). Thus in the present study, cell block has proven to be a minimally invasive diagnostic tool providing as good as results of diagnosis of invasion in ductal carcinoma of breast as core needle biopsy with minimal risk of complication of seeding of needle track by tumor cells as compared to core needle biopsy (Figures 5-7).

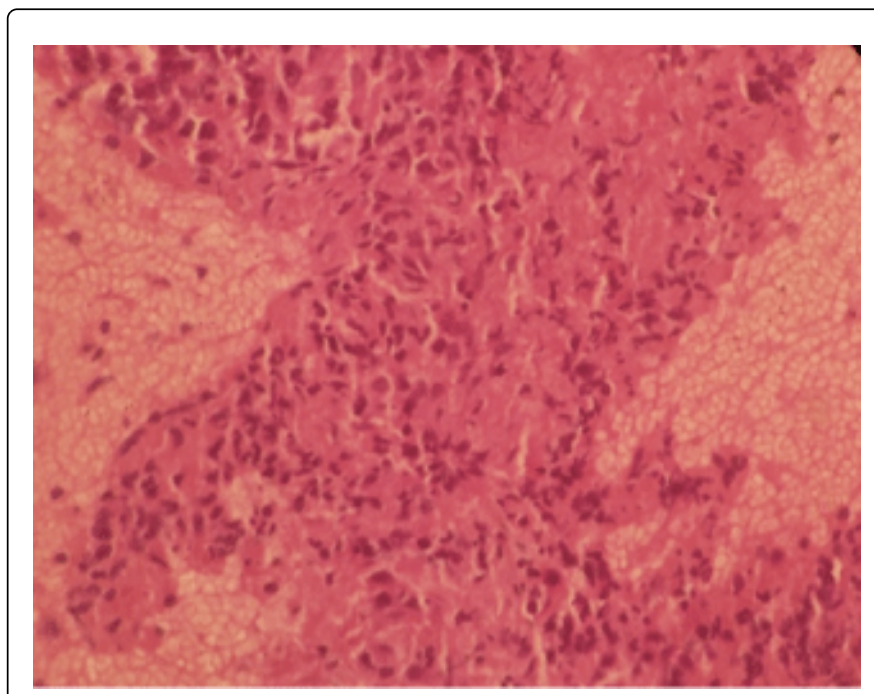

Figure 5: Photomicrograph showing malignant ductal cells in the stroma with some activation of stromal cells diagnosed as invasive ductal carcinoma on cell block ( $x 400, H \& E$ stain).

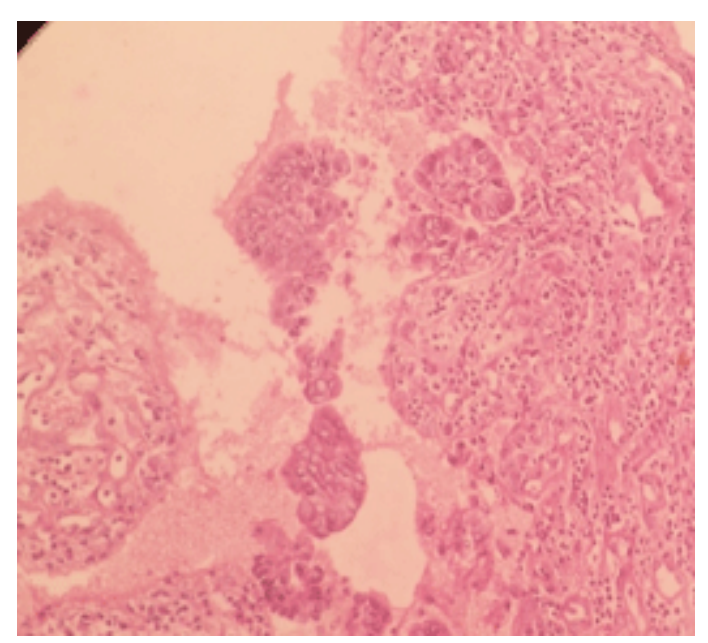

Figure 6: Photomicrograph showing malignant cells in the stroma having ductal pattern diagnosed as invasive ductal carcinoma on cell block (x200, H\&E stain).

Major limitation of fine needle aspiration compared with core needle biopsy is the inability to determine whether a cancer is invasive. Cell blocks complement smears and monolayers and appear to overcome major limitations of breast FNA. One of the benefits of combining cell blocks with smears or monolayer preparations is the ability to see the histologic correlates of cytologic findings. Some cytologic criteria cannot be translated into the histologic criteria used by surgical pathologists. 
Page 5 of 5

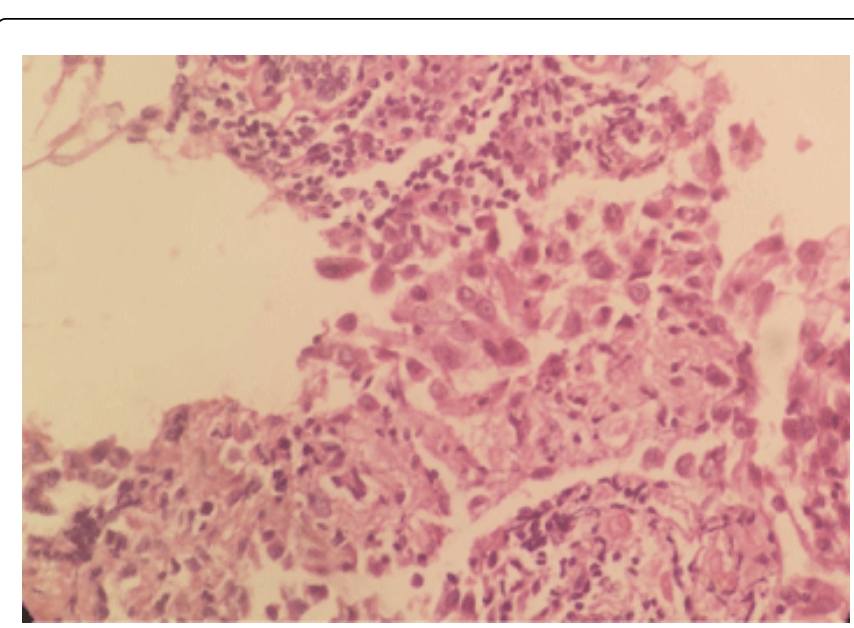

Figure 7: Photomicrograph showing malignant ductal cells in the stroma having lymphocytic infiltrate surrounding them on cell block (x400, H\&E stain).

Since there are separate criteria used by surgical pathologists and cytologists, cell block sections tend to complement FNA smears. This complementary nature of cell blocks and FNAC smears/monolayers could be expected to help avoid pitfalls of using either cytology or histology alone [9]. This concept is supported by studies that have shown that combining core needle biopsy with FNA improves diagnostic accuracy compared to either test alone [2]. This study suggests that combining a smear preparation of breast FNA with the cell block can also combine the advantages of both approaches. The sensitivity was $96 \%$, specificity was $100 \%$, positive predictive value was $100 \%$, negative predictive value was $100 \%$ and total accuracy was $96 \%$.

\section{Statistical indices by combined utility of FNAC and cell block:}

- Sensitivity $96 \%$

- Specificity $100 \%$

- Positive predictive value $100 \%$

- Negative predictive value $100 \%$
- Accuracy $96 \%$.

\section{Conclusion}

Cell block helps to overcome limitation of breast FNA by its ability to diagnose invasion in ductal carcinoma of breast. Cell block bridges the gap between cytology and histopathology by its property to complement FNA smears. Cell block method provides high cellularity and preservation of architectural patterns. This property helps in establishing more definitive cytopathological diagnosis as well as classification of malignancy. Based on this open biopsies can be avoided. Immunohistochemistry can be performed on serial sections which can help to subtype certain tumors and find a primary site in case of metastasis.

\section{References}

1. Kulkarni MB, Prabhudesai NM, Desai SB (2000) Scrape cell block technique for fine needle aspiration cytology smears. Cytopathology 11: 179-184.

2. Westenend PJ, Sever AR, Beekman-De VHJ (2001) A comparison of aspiration cytology and core needle biopsy in the evaluation of breast lesions. Cancer Cytopathol 93: 146-150.

3. Orrel \& Sterrett's fine needle aspiration cytology, (5thedn), p: 159.

4. Istvanic S, Fischer AH, Banner BF (2007) Cell blocks of breast FNAs frequently allow diagnosis of invasion or histological classification of proliferative changes. Diagn Cytopathol 35: 263-269.

5. Bales CE (2006) Laboratory techniques. In: Koss LG, Melamed MR (eds.) Koss' Diagnostic cytology and its histopathologic bases, (5thedn), Lippincott Williams \& Wilkins, Philadelphia 2006: 1590-1593.

6. Zito FA, Gadaleta CD, Salvatore (1995) A modified cell block technique for fine needle aspiration cytology. Acta Cytol 39: 93-99.

7. Domagala WM, Markiewski M, Tuziak T (1990) Immunocytochemistry on fine needle aspirates in paraffin miniblocks. Acta Cytol 34: 291-296.

8. Jackman RJ, Burbank F, Parkar SH (2001) Stereotactic breast biopsy of nonpalpable lesions: Determinants of ductal carcinoma in situ underestimation rates. Radiology 218: 497-502.

9. Baloch ZW, Tam D, Langer J (2000) Ultrasound guided fine needle aspiration biopsy of the thyroid: role of on site assessment and multiple cytologic preparations. Diagn Cytopathol 23: 425-429. 